\title{
Environmental aspects of using gas chromatography for determination of pharmaceutical residues in samples characterized by different composition of the matrix
}

\author{
Joanna Sadkowska*, Magda Caban, Mariusz Chmielewski, Piotr Stepnowski, \\ Jolanta Kumirska
}

University of Gdańsk, Poland

*Corresponding author's e-mail: joanna.sadkowska@ug.edu.pl

Keywords: GC and GC-MS analyses, pharmaceutical residues, sector application of gas chromatography.

\begin{abstract}
This paper aims at presenting the possibilities of applying gas chromatography for the determination of pharmaceutical residues in different matrices. Section one of the study underscores the environmental advantages of employing GC for such analyses. Section two presents the innovative methods for determining pharmaceuticals in the environment. The last section discusses the results of the analysis of the GC and GC-MS market in Poland.

According to the literature data, the described methods were applied for the analysis of real samples: wastewaters, surface waters, soil samples. The samples were collected from the Pomerania region and the Gulf of Gdańsk. The pharmaceuticals were determined in various environmental samples. The highest concentrations were found in raw wastewater, medium - in a treated wastewater, and the lowest - in surface water. The most frequently detected pharmaceuticals were: ibuprofen, paracetamol, diclofenac and naproxen, all belonging to NSAIDs.

Furthermore, the results of the study of the Polish GC market indicate that a very limited number of entities are currently using chromatographic techniques, and pharmaceutical residues tests are exceptions, mainly due to the lack of the legal requirements in this field and the lack of own laboratories.
\end{abstract}

\section{Environmental advantages of using gas chromatography for determination of pharmaceutical residues in different matrices}

Gas chromatography (GC) and liquid chromatography (LC) are more than 50 years old (Jennings \& Poole 2012, Snyder and Dolan 2013). Several improvements and innovations were implemented in the last 20 years, and currently GC and LC techniques are one of the most often used for the analytical purposes. For example, these two techniques enable determining pharmaceutical residues in different matrices including biological, cosmetics, food and environmental samples (e.g. Petrović et al. 2005, Görög 2011, Primel et al. 2012, Tadeo et al. 2012, Núñez et al. 2012, Mohamed 2015, Puckowski et al. 2016, Afonso-Olivares et al. 2016). They are usually used for monitoring studies, routine analysis, stability studies and quality control.

Today, the presence of pharmaceuticals in the environment (PiE) is a topic of interest for society in general and for the scientific community in particular (Daughton 2016, der Beek et al. 2015) (Ziembińska-Buczyńska et al. 2015). Many dimensions involved with $\mathrm{PiE}$ span over 70 years of published literature, however $\mathrm{PiE}$ as a field of research has displayed exponential growth since the late 1990s. This is due to their ubiquity in the aquatic environment at ng/l levels, their ecotoxicological/health effects and the lack of government regulations. For example, thanks to the $\mathrm{GC}$ techniques the first report about clofibric acid in natural water was presented in 1981 (Kot-Wasik Dębska and Namieśnik 2007).

Currently, the standard analytical technique for determining pharmaceuticals in different matrices has hitherto been liquid chromatography coupled with mass spectrometry (LC-MS) or tandem mass spectrometry (LC-MS/MS) (Fatta et al. 2007, Primel et al. 2012, Tadeo et al. 2012, Puckowski et al. 2016, Afonso-Olivares et al. 2016, Bletsou et al. 2016). Despite its many advantages, particularly the considerable simplification of sample preparation, this technique has a number of drawbacks. These include the interference of analytes with matrix components, which directly affects the method quantification limit (MQL) and method detection limit (MDL), problems with repeatability and reproducibility of results, the significant effect of the type of mobile phase on the efficacy of analyte ionization and fragmentation, the lack of a mass spectra library, and the high cost of LC-MS analysis (Reemtsma 2001, Zwiener and Frimmel 2004)

An interesting alternative is gas chromatography, especially when the target drugs are present at very low concentrations in complex matrices, and when such matrices negatively influence the proper determination of these compounds by means of LC-MS/MS. The lower cost of GC analysis and the smaller amounts of solvent consumed also favour such approach. It was also reported that the limits of pharmaceuticals' detection are 
often smaller when GC was used, compared to the LC technique (Kot-Wasik et al. 2007, Görög 2011, Shaaban and Górecki 2015). Moreover, the widespread availability of the relevant instruments in laboratories means that GC is an excellent tool for identifying and quantifying pharmaceuticals in different matrices which can be implemented in routine analysis in environmental, clinical and food analysis laboratories much more quickly.

GC is already used as a reference technique for water pollutants, polycyclic aromatic hydrocarbons among others (Pistelok and Jureczko 2014).

Current trends in green liquid chromatography, including also green trends in gas chromatography, for the analysis of pharmaceutically active compounds in the environmental water compartments, are presented by Shaaban and Górecki (2015). The main approaches used to make GC greener are presented in Fig. 1.

Green, environmentally-friendly, analytical tools in pharmaceuticals and cosmetics analysis are presented by Mohamed (2015). On the other hand, it is worth mentioning that the protocols based on the GC and LC techniques for conducting pharmaceutical residues analysis are similar in the extraction step, which is normally the solid phase extraction (Caban et al. 2015). However, because most of the pharmaceuticals are polar or highly polar compounds, these have first to be converted into suitable, volatile derivatives prior to GC analysis (Blau and Darbre 1993, Orata 2012).

Many analysts find derivatization (especially its optimization) a time-consuming and labour-intensive step and try to avoid it in analytical procedures. Instead of using GC-MS or GC-MS/MS, they prefer to use liquid chromatography coupled with mass spectrometry (LC-MS or LC-MS/MS). The capillary electrophoresis (CE) coupled with MS is another option (exemplary application for pharmaceuticals analysis can be found in (Dawod et al. 2010, Himmelsbach et al. 2005), not popular, despite the fact that this technique is environmentally friendly (Xie and He 2010). On the other hand, an inter-laboratory study has demonstrated that with regard to sensitivity and measurement uncertainty, GC-MS may be superior to LC-MS for the trace analysis of organic compounds in matrices of greater complexity (Gentili 2007, Heath et al. 2010). Thus, the development of pharmaceutical derivatization procedure of new derivatizing reagents and of quality control methodologies are very important tasks in the modern analysis of such compounds. The application of GC techniques for the determination of pharmaceuticals in environmental samples is presented below.

\section{Methods for determining pharmaceutical residues in environment - literature review}

The two main techniques used for the determination of pharmaceuticals in environmental samples are GC-MS and LC-MS. It is observed that in the previous years most of the analytical protocols had been based on LC-MS (Kim and Carlson 2005, Ternes 2001, Petrović et al. 2005, Görög 2011, Primel et al. 2012, Tadeo et al. 2012) (Chunhui et al. 2016). However, during the last years many analytical protocols based on GC/MS techniques were developed and applied around the world for residuals analyses in environmental samples (Caban et al. 2015, Naing Li \& Lee 2015, Omar et al. 2016, Puckowski et al. 2016, Afonso-Olivares et al. 2016).

We have also developed a series of methods for determination of pharmaceutical residues using GC and GC-MS technique (Caban et al. 2013, Kumirska et al. 2015, Migowska et al. 2012). The groups of investigated pharmaceuticals were: estrogen hormones, non-steroidal anti-inflammatory drugs (NSAIDs), anti-epileptics, anti-depressants, beta-blockers and beta-agonists. All mentioned pharmaceuticals are commonly used in Poland and in other countries. The starting point of the aforementioned study was optimization of derivatisation reaction for mixtures of analytes, using an advanced chemometric analysis or

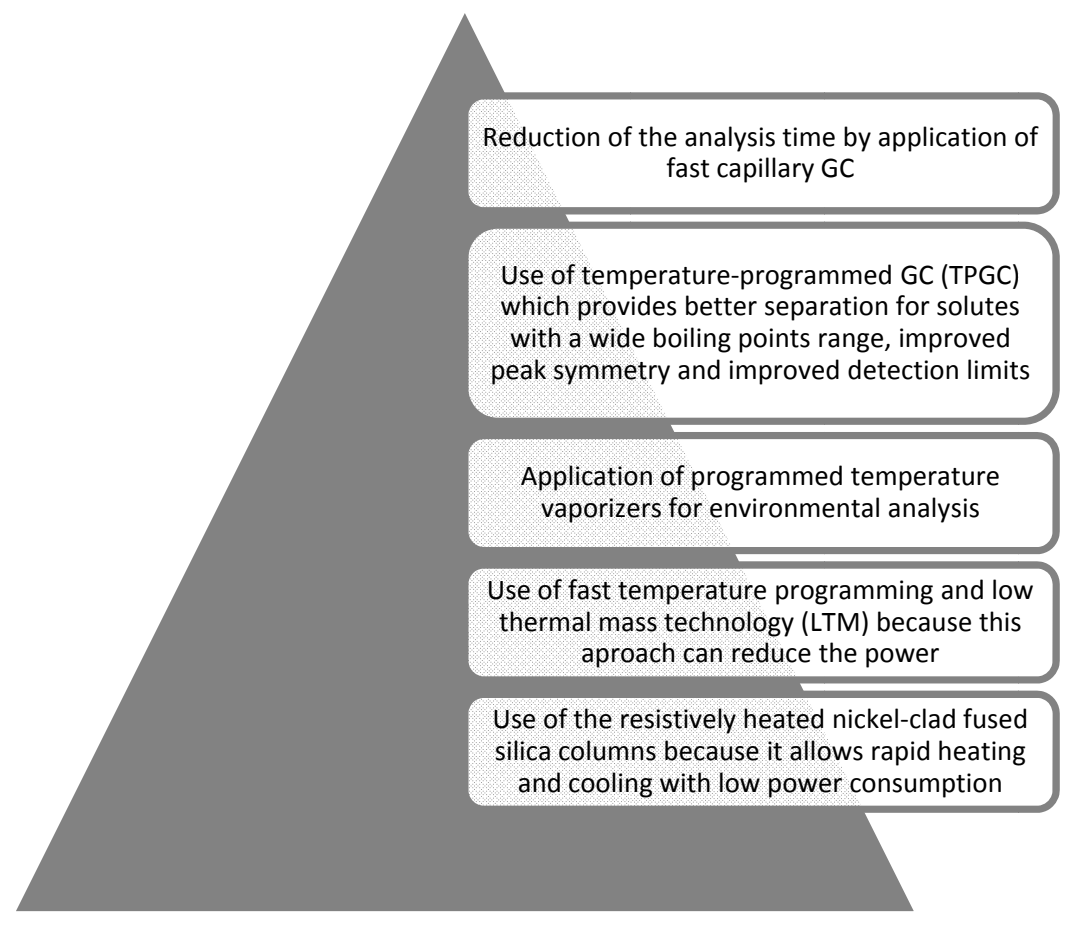

Fig. 1. The main approaches which are used to make GC greener in the analysis of pharmaceuticals in the environmental samples (Shaaban and Górecki 2015) 
a single-step optimization (Caban et al. 2011, Kumirska et al. 2011, Kumirska et al. 2013). Several reactions were tested, and a silylation was proven to be the most efficient. What is essential, the final derivatisation condition gives high and repeatable detector response for all target pharmaceuticals. The additional step of derivatisation, which discourages some researchers from using GC, was proven to be fast and convenient. The next step was to develop extraction techniques, which allow an efficient and selective extraction of target pharmaceuticals. The main problem was to develop a protocol which would enable efficient extraction of analytes differences in chemical properties. Several protocols were developed for water samples (Migowska et al. 2012) and solid samples (Kumirska et al. 2015). The last step was to validate a methodology that could be repeatable and, with every usage, would give accurate and precise results. The developed methods were tested using real samples spiked by target analytes.

The developed protocols were applied for the analysis of real samples: wastewaters, surface waters, soil samples. The above samples were collected from Pomerania region and the Gulf of Gdańsk. Pharmaceuticals were determined in various environmental samples. The highest concentrations were found in raw wastewater, medium - in a treated wastewater, and the lowest-in surface water (Table 1). The most frequently detected pharmaceuticals were: ibuprofen, paracetamol, diclofenac and naproxen, all belonging to NSAIDs. This should be attributed to the fact that the above-listed pharmaceuticals are over-the-counter drugs and as a result are commonly used in Poland. They also had a low potential for removal in wastewater treatment plants. The estrogen hormones were found in all samples types, while their high concentration was identified in raw wastewaters. The beta-blockers (pharmaceuticals used in hypertension) were found only in water samples, and in high amounts in wastewaters. The results of mentioned screening gives valuable information about the pharmaceutical occurrence in environment. Generally, the concentrations of pharmaceuticals found in environment are low and cannot have direct negative impact on living organism, however information about its long-term effect (especially regarding reproduction) is missing (Caldwell et al. 2014). What is more, in a real situation pharmaceuticals work negatively with a mixture of other pollutants (Geiger et al. 2016).

Thus, it can be stated that GC-MS technique is a highly reliable tool for the determination of pharmaceutical residual in environmental samples. This is due to the desired limits of detection, low sensitivity to matrix interferences and high repeatability of results. Taking into consideration high reliability of results obtained, the presented protocols can be used as a perfect tool for long term monitoring of pharmaceutical residues. This data is necessary to asses risk of its presence and potential negative impact on human health.

In addition, the GC, compared to the LC-based techniques, is known to be a green and environmentally friendly technique (Biswas and Mitra 2013) replacing conventional GC. The appreciating feature of green GC is it/u2019s environment-friendliness by the way of reducing/eliminating the amount of solvents required for sample preparation and amount of waste generation or emission of volatile products.

It should also be emphasized that the scope of potential areas where the aforementioned methodologies (including the stage of derivatization of analytes and then analysis itself) can be adjusted to be applied for the purpose of entities responsible for the assessment of food quality, pharmaceuticals quality, as well the anti-doping control.

Table 1. Examples of NSAIDs detection in environmental samples collected in Poland

\begin{tabular}{|c|c|c|c|c|c|c|c|}
\hline \multirow[b]{2}{*}{ Pharmaceutical } & \multicolumn{7}{|c|}{ Concentration found - ng/L (water) or ng/g (solids) } \\
\hline & Raw wastewater & $\begin{array}{c}\text { Treated } \\
\text { wastewater }\end{array}$ & Sludge & $\begin{array}{l}\text { River } \\
\text { Vistula }\end{array}$ & $\begin{array}{l}\text { Bolszewo } \\
\text { fish ponds } \\
\text { (sediment) }\end{array}$ & $\begin{array}{l}\text { Gdańsk } \\
\text { Jasień } \\
\text { (soil) }\end{array}$ & $\begin{array}{l}\text { Gdańsk } \\
\text { Szadółki } \\
\text { (soil) }\end{array}$ \\
\hline \multicolumn{8}{|c|}{ NSAIDs } \\
\hline Ibuprofen & 280 & 110 & 96 & 43.0 & 1.0 & 8.0 & 5.0 \\
\hline Naproxen & 240 & $70-120$ & 10 & - & - & - & - \\
\hline Diclofenac & $263-460$ & 134 & 20 & - & 2.1 & - & - \\
\hline Paracetamol & 530 & 434 & - & 144.4 & - & - & - \\
\hline Flurbiprofen & $<M Q L-195.2$ & - & - & - & - & 8.8 & 6.5 \\
\hline Diflunisal & $<M Q L$ & - & - & 58.8 & - & - & - \\
\hline \multicolumn{8}{|c|}{ Hormones } \\
\hline Estrone & - & - & - & - & - & - & 6.5 \\
\hline 17beta-estradiol & - & - & - & - & 1.2 & 9.0 & - \\
\hline Estriol & 377.5 & 53.6 & - & - & - & - & 6.9 \\
\hline \multicolumn{8}{|c|}{ Beta-blockers and beta-agonists } \\
\hline Terbutaline & 221.1 & - & - & $<\mathrm{MQL}$ & - & - & - \\
\hline Salbutamol & 240.0 & - & - & 43.0 & - & - & - \\
\hline Propranolol & 723.3 & 193.9 & - & - & - & - & - \\
\hline Nadolol & - & 183.1 & - & - & - & - & - \\
\hline Pindolol & 680.8 & 192.0 & - & - & - & - & - \\
\hline
\end{tabular}

Source: (Caban et al. 2014, Migowska et al. 2012, Kumirska et al. 2015). 


\section{Quality assurance/quality control (QA/QC) procedures}

It is well known that application of proper quality assurance/ quality control $(\mathrm{QA} / \mathrm{QC})$ procedures is crucial for obtaining the results which could be treated as a source of reliable analytical information (Konieczka and Namieśnik 2009, Thompson et al. 2000, Karageorgou and Samanidou 2014). For this reason all analytical methods for determining pharmaceuticals environmental/biological/food samples should be validated. These experiments should be performed using spiked and non-spiked samples and working calibration standard solutions and matrix-matched calibration solutions. The validation parameters of each method such as linearity range, correlation coefficient $\left(\mathrm{R}^{2}\right)$, intra-day precision (RSD [\%]), accuracy [\%], method detection limit (MDL), method quantification limit (MQL), matrix effect (ME) $[\%]$ and absolute recovery (AR) [\%] should be determined. All the mentioned above QA/QC data were established and presented in the cited literature and were satisfactory.

\section{Opportunities to use gas chromatography for determining pharmaceuticals in different sectors of economy - study of the Polish market}

The objective of the study was to: 1. identify the entities currently providing pharmaceutical residues determination services in the Polish market; 2 . identify and examine potential entities interested in implementing an innovative method for the determination of pharmaceuticals in the environment with use of GC and GC-MS from the following sectors: food, pharmaceutical and biomedical, health care and institutions such as sanitary-epidemiological stations, veterinary inspectorates and inspectorates for environmental protection; 3. examine the constraints that determine use of GC and GC-MS by the studied entities in Poland.

The study on the possibility of implementing innovative methods for the determination of residues of pharmaceuticals in the environment using GC, GC-MS was carried out between 20.07-10.08.2015. The research was conducted in the following order: 1. preliminary study of the literature in the knowledge area of analytical methods (gas chromatography), 2. preliminary findings and further research, 3. in-depth study of the literature and empirical data 4. collection of information and data 5. data analysis 6 . formulating conclusions on the basis of the obtained results. Empirical research was conducted with a diagnostic survey method (Forza 2002, Pinsonneault and Kraemer 1993) in two ways: using in-depth telephone interview, and using the questionnaire, which was sent to 2348 entities. A total analysis covered 388 subjects (based on 350 full interview questionnaires and 33 correctly filled e-mail questionnaires).

Among the tested companies and other entities $(\mathrm{N}=388)$, gas chromatography was used by 135 entities (to compare, HPLC was used by 127 and LC-MS by 56 entities). GC-MS was used by 89 entities. GC and HPLC are most commonly used because they do not require skilled operators and the price of the equipment is low. Besides, the two techniques are sufficient for quantitative analyses in most sectors (food, cosmetics and pharmaceuticals), where the analyte concentrations are high. On the other hand, the application of MS detector in GC-MS and LC-MS is associated with a significantly higher service costs (operation cost and work of technician) and is useful in sectors such as: criminology, clinical and environmental analysis, where sensitive and selective detectors are required (this factor is associated with low concentrations of analytes). Increased applicability of GC-MS in comparison to LC-MS is associated with a lower cost of equipment purchase, although the second one covers a wider range of analytes possible to determine with a detector.

GC is used primarily by sanitary-epidemiological stations, veterinary inspectorates, inspectorates for environmental protection and inspectorates for commercial quality of agri-food products. This situation results from the influence of legal regulations that require particular entities to use a specific set of techniques in order to carry out their statutory duties. Gas chromatography is also used by the police (test laboratories) and by test laboratories conducting commercial activities. Among the studied entities which use 'a full package' of techniques $(\mathrm{n}=41)$ for tests (GC, GC-MS, HPLC, LC-MS) are mainly state-owned entities: research institutes (9), provincial sanitary - epidemiological stations (8), inspectorates for environmental protection (8), veterinary inspectorates (5), and entities providing analytical services for the courts (2), and analyses of environmental samples (3), and those dealing with sewage and water treatment (1). In the group of privately owned business the following were identified: commercial test laboratories (2), and manufacturing firms (3). Given the total number of entities using chromatographic techniques, it should be emphasized that a small number of them use all the methods based on LC and $\mathrm{GC}$ techniques. This should be attributed mainly to the high cost related to working with all the techniques listed above.

The techniques used for the purpose of determining pharmaceutical residues were in most cases liquid chromatography techniques (29 entities), gas chromatography techniques (17 entities) and other methods including UV detection, microbiological methods and Elisa tests (9 entities). However, pharmaceutical residue analyses in the environment have been carried out only by 7 researched entities: universities, private analytical laboratories, research institutes and national laboratories for environmental analysis.

The analyzed entities were also asked whether they are planning to implement pharmaceutical residues tests in the near future. Great majority (338) of the 388 analyzed units indicated that they are not interested, and consequently do not intend to or cannot implement tests of pharmaceutical residues in selected matrices. The following factors were indicated as the reasons that block or prevent the introduction of pharmaceutical residue analyses: high analysis cost (1 answer), high cost of equipment (3), limitations of the techniques related to volatility of analytes (1), sensitivity to water content, lack of equipment. No surveyed entity did indicate the complexity of operation as the reason, because of which analysis of pharmaceutical residues will be not implemented. Only 34 entities declared interest or intention to implement this solution in the future. This group included first of all entities which already provide services related to determining pharmaceutical residues: research institutes in the area of environmental protection and academic research (11 entities), veterinary inspectorates (6), environmental protection inspectorates (4), water and sewage treatment companies (2). What is significant however is the fact new entities such as police (1), pharmaceutical manufacturing firms (5), cosmetics producers (1) declared their intention to determine residues of pharmaceuticals. This fact should be attributed mainly to two 
groups of factors. The first results from the growing consciousness and knowledge referring to the fact that the environment is to a high extent exposed to the negative influence of pharmaceutical residues and the potential impact it can have on human health. The second one refers to the competitive advantages offered by gas chromatography in the process of determining pharmaceutical residues - compared to other techniques.

The results of this study allow us to draw the following conclusions. A very small number of entities are currently using chromatographic techniques, and pharmaceutical residues tests are exceptions, mainly due to the lack of legal requirements in this area and the lack of own laboratories. For a significant number of small businesses (employing 10 to 49 employees), lack of knowledge about chromatography is also noticeable. The low popularity of analysis of pharmaceutical residues is also determined by the belief that these analyses are not in the business profile of a company (this is particularly noticeable in the case of the companies operating water supply networks) and low demand for this type of analyses (one respondent described it as a hermetic niche). The problem may also arise from the fact that some survey respondents did not differentiate between analysis of pharmaceuticals and analysis of residues of pharmaceuticals and identified the latter mainly as antibiotic residues.

Currently, in Poland and in other countries in the UE there is no legal regulation for the limits of pharmaceuticals in environmental samples. It should be emphasized that the popularity of the chromatographic methods used for the determination of residues of pharmaceuticals in the environment will be strongly influenced by regulations entering into force and increasing the demand for this type of research. Some of the respondents expect a change in the law relating to the guidelines of the WHO and the EU Water Directive, but the date of the introduction of new regulations remains unknown - with forecast dating from 2016 until 2020. In the case of state institutions, a decision regarding the choice of techniques for determining residues of pharmaceuticals will be made top-down.

\section{Conclusions}

Gas chromatography has several features which make it an optimum tool for monitoring pharmaceuticals in different samples. Firstly, the 'economics' of GC application (purchase, media consumption, cost of a single analysis) is more competitive than those for a LC. Secondly, there are already developed methods, which are validated and ready to use by the monitoring organs. The GC equipment is available as well. Finally, the GC is much more environmentally friendly than the LC techniques due to its waste-free work and lower energy consumption.

Among the studied Polish companies and other entities $(\mathrm{N}=388), 135$ were using gas chromatography. Gas chromatography is applied mainly by sanitary-epidemiological stations, veterinary inspectorates, inspectorates for environmental protection and inspectorates for commercial quality of agri-food products. However, only 34 entities declared interest or intention to implement this solution in the future. It should be emphasized that the popularity of the chromatographic methods used for determining pharmaceuticals in the environment will be strongly influenced by regulations entering into force and increasing the demand for this type of research. In the case of state institutions, a decision regarding the choice of techniques for determining residues of pharmaceuticals will be made top-down.
The analysed pharmaceuticals representing the following classes: estrogen hormones, non-steroidal anti-inflammatory drugs (NSAIDs), beta-blockers, beta-agonists, anti-epileptics, anti-depressants- due to their common usage are commonly found in the environment. As a consequence they should be treated as a real danger for the environment and for human health. Presented protocols can be used as a perfect tool for long term monitoring of pharmaceutical residues in the environment and in this way protecting people's health.

\section{Ackonwledgements}

The project 'Analysis of the implementation possibilities of the innovative methods for determining pharmaceuticals in environmental, clinical and food samples using GC and GC-MS" has been financially supported by the Polish National Centre for Research and Development within the grant number TANGO1/268806/NCBR/2015.

\section{References}

Afonso-Olivares, C., Montesdeoca-Esponda, S., Sosa-Ferrera, Z. \& Santana-Rodríguez, J.J. (2016). Analytical tools employed to determine pharmaceutical compounds in wastewaters after application of advanced oxidation processes, Environmental Science and Pollution Research, 23, pp. 24476-24494.

Biswas, D. \& Mitra, D. (2013). Green techniques in gas chromatography, In: Green Chromatographic Techniques (pp. 103-212), Springer Netherlands 2013.

Blau, K. \& Darbre, A. (1993). Handbook of derivatives for chromatography, New York: Wiley 1993.

Bletsou, A.A., Jeon, J., Hollender, J., Archontaki, E. \& Thomaidis, N.S. (2015). Targeted and non-targeted liquid chromatography-mass spectrometric workflows for identification of transformation products of emerging pollutants in the aquatic environment, Trends in Analytical Chemistry, 66, pp. 32-44.

Caban, M., Kumirska, J. \& Bialk-Bielińska, A. (2015). Current issues in pharmaceutical residues in drinking water, Current Analytical Chemistry, 12, pp. 249-257.

Caban, M., Mioduszewska, K., Stepnowski, P., Kwiatkowski, M. \& Kumirska, J. (2013). Dimethyl(3,3,3-trifluoropropyl) silyldiethylamine-A new silylating agent for the derivatization of $\beta$-blockers and $\beta$-agonists in environmental samples, Analytica Chimica Acta, 782(2012), pp. 75-88. http://doi.org/10.1016/j. aca.2013.04.018

Caban, M., Stepnowski, P., Kwiatkowski, M., Migowska, N. \& Kumirska, J. (2011). Determination of $\beta$-blockers and $\beta$-agonists using gas chromatography and gas chromatography-mass spectrometry-a comparative study of the derivatization step, Journal of Chromatography A, 1218(44), pp. 8110-8122. http://doi.org/10.1016/j.chroma.2011.08.093

Dawod, M., Breadmore, M.C., Guijt, R.M. \& Haddad, P.R. (2010). Electrokinetic supercharging-electrospray ionisation-mass spectrometry for separation and on-line preconcentration of hypolipidaemic drugs in water samples, Electrophoresis, 31(7), pp. 1184-1193. http://doi.org/10.1002/elps.200900420

Daughton, C.G. (2016). Pharmaceuticals and the Environment (PiE): Evolution and impact of the published literature revealed by bibliometric analysis, Science of the Total Environment, 562, pp. 391-426.

Der Beek, T.A., Weber, F.A., Bergmann, A. Hickmann, S., Ebert, I., Hein, A. \& Küster, A. (2016). Pharmaceuticals in the environment-global occurrences and perspectives, Environmental Toxicology and Chemistry, 35(4), pp. 823-835. 
Fatta, D., Achilleos, A., Nikolaou, A. \& Meriç, S. (2007). Analytical methods for tracing pharmaceutical residues in water and wastewater, Trends in Analytical Chemistry, 26(6), pp. 515-533. http://doi.org/10.1016/j.trac.2007.02.001

Forza, C. (2002). Survey research in operations management: a process-based perspective, International Journal of Operations \& Production Management, 22(2), 152. http://doi.org/10.1108/01443570210414310

Gentili, A. (2007). Determination of non-steroidal anti-inflammatory drugs in environmental samples by chromatographic and electrophoretic techniques, Analytical and Bioanalytical Chemistry, 387(4), pp. 1185-1202. http://doi.org/10.1007/s00216-006-0821-7

Görög, S. (2011). Advances in the analysis of steroid hormone drugs in pharmaceuticals and environmental samples (2004-2010), Journal of Pharmaceutical and Biomedical Analysis, 55(4), pp. 728-743. http://doi.org/10.1016/j.jpba.2010.11.011

Heath, E., Kosjek, T., Farre, M., Quintana, J.B., de Alencastro, L.F., Castiglioni, S. \& Barcelo, D. (2010). Second interlaboratory exercise on non-steroidal anti-inflammatory drug analysis in environmental aqueous samples, Talanta, 81(4-5), pp. 1189-1196. http://doi.org/10.1016/j.talanta.2010.02.009

Himmelsbach, M., Klampfl, C.W. \& Buchberger, W. (2005). Development of an analytical method for the determination of antidepressants in water samples by capillary electrophoresis with electrospray ionization mass spectrometric detection, Journal of Separation Science, 28(14), pp. 1735-1741. http://doi. org/10.1002/jssc.200500157

Jennings, W.G. \& Poole, C.F. (2012). Chapter 1-Milestones in the Development of Gas Chromatography, Gas Chromatography, pp. 1-17. http://doi.org/http://dx.doi.org/10.1016/B978-0-12385540-4.00001-8

Karageorgou, E. \& Samanidou, V. (2014). Youden test application in robustness assays during method validation, Journal of Chromatography A, 1353, pp. 131-139.

Kim, S.-C. \& Carlson, K. (2005). LC-MS2 for quantifying trace amounts of pharmaceutical compounds in soil and sediment matrices, Trends in Analytical Chemistry, 24(7), pp. 635-644.

Konieczka, P. \& Namieśnik, J. (2009). Quality assurance and quality control in theanalytical chemical laboratory: a practical approach, CRC Press/Francis and Taylor, Boca Raton, FL, 2009.

Kot-Wasik, A., Dębska, J. \& Namieśnik, J. (2007). Analytical techniques in studies of the environmental fate of pharmaceuticals and personal-care products, $\operatorname{Tr} A C$ Trends in Analytical Chemistry, 26(6), pp. 557-568. http://doi.org/10.1016/j.trac.2006.11.004

Kumirska, J., Migowska, N., Caban, M., Łukaszewicz, P. \& Stepnowski, P. (2015). Simultaneous determination of non-steroidal anti-inflammatory drugs and oestrogenic hormones in environmental solid samples, The Science of the Total Environment, 508, pp. 498-505. http://doi.org/10.1016/j.scitotenv.2014.12.020

Kumirska, J., Migowska, N., Caban, M., Plenis, A. \& Stepnowski, P. (2011). Chemometric analysis for optimizing derivatization in gas chromatography-based procedures, Journal of Chemometrics, 25(12), pp. 636-643. http://doi.org/10.1002/cem.1410

Kumirska, J., Plenis, A., Łukaszewicz, P., Caban, M., Migowska, N., Białk-Bielińska, A., Czerwicka, M. \& Stepnowski, P. (2013). Chemometric optimization of derivatization reactions prior to gas chromatography-mass spectrometry analysis, Journal of Chromatography A, 1296, pp. 164-178. http://doi.org/10.1016/j. chroma.2013.04.079

Mohamed, H.M. (2015). Green, environment-friendly, analytical tools give insights in pharmaceuticals and cosmetics analysis, Trends in Analytical Chemistry, 66, pp. 176-192.

Migowska, N., Caban, M., Stepnowski, P. \& Kumirska, J. (2012). Simultaneous analysis of non-steroidal anti-inflammatory drugs and estrogenic hormones in water and wastewater samples using gas chromatography-mass spectrometry and gas chromatography with electron capture detection, The Science of the Total Environment, 441, pp. 77-88. http://doi.org/10.1016/j. scitotenv.2012.09.043

Naing, N.N., Li, S.F.Y. \& Lee, H.K. (2015). Graphene oxide-based dispersive solid-phase extraction combined with in situ derivatization and gas chromatography-mass spectrometry for the determination of acidic pharmaceuticals in water, Journal of Chromatography A, 1426, pp. 69-76. http://doi.org/10.1016/j.chroma.2015.11.070

Núñez, O., Gallart-Ayala, H., Martins, C.P.B. \& Lucci, P. (2012). New trends in fast liquid chromatography for food and environmental analysis, Journal of Chromatography A, 1228, pp. 298-323

Omar, T.F.T., Ahmad, A., Aris, A.Z. \& Yusoff, F.M. (2016). Endocrine disrupting compounds (EDCs) in environmental matrices: Review of analytical strategies for pharmaceuticals, estrogenic hormones, and alkylphenol compounds, TrAC-Trends in Analytical Chemistry, 85, pp. 241-259. http://doi.org/10.1016/j.trac.2016.08.004

Orata, F. (2012). Derivatization reactions and reagents for gas chromatography analysis, Advanced Gas Chromatography - Progress in Agricultural, Biomedical and Industrial Applications, pp. 83-156. http://doi.org/10.5772/33098

Petrović, M., Hernando, M.D., Díaz-Cruz, M.S. \& Barceló, D. (2005). Liquid chromatography-tandem mass spectrometry for the analysis of pharmaceutical residues in environmental samples: a review, Journal of Chromatography A, 1067, pp. 1-14.

Pinsonneault, A. \& Kraemer, K.L. (1993). Survey research methodology in management information systems: an assessment, Journal of Management Information Systems, 10(2), pp. 75-105. http://doi.org/1175042

Primel, E.G, Caldas, S.S. \& Escarrone, A.L.V. (2012). Multi-residue analytical methods for the determination of pesticides and PPCPs in water by LC-MS/MS: a review, Central European Journal of Chemistry, 10(3), pp. 876-899.

Puckowski, A., Mioduszewska, K., Łukaszewicz, P., Borecka, M., Caban, M., Maszkowska, J. \& Stepnowski, P. (2016). Bioaccumulation and analytics of pharmaceutical residues in the environment: A review, Journal of Pharmaceutical and Biomedical Analysis, 127, pp. 232-255.

Reemtsma, T. (2001). The use of liquid chromatography-atmospheric pressure ionization-mass spectrometry in water analysis - Part II: Obstacles, Trends in Analytical Chemistry, 20(10), pp. 533-542.

Shaaban, H. \& Górecki, T. (2015). Current trends in green liquid chromatography for the analysis of pharmaceutically active compounds in the environmental water compartments, Talanta, 132, pp. 739-752.

Snyder, L.R. \& Dolan, J.W. (2013). Milestones in the Development of Liquid Chromatography. Liquid Chromatography: Fundamentals and Instrumentation, Elsevier Inc. 2013, http://doi.org/10.1016/ B978-0-12-415807-8.00001-8.

Tadeo, J.L, Sánchez-Brunete, C., Albero, B., García-Valcárcel, A.I. \& Pérez, R.A. (2012). Central European Journal of Chemistry, 10(3), pp. 480-520.

Thompson, M., Ellison, S.L.R. \& Wood, R. (2000). Harmonized guidelines forsingle-laboratory validation of methods of analysis (IUPAC TechnicalReport), Pure and Applied Chemistry, 74, pp. 835-855.

Ternes, T.A. (2001). Analytical methods for the determination of pharmaceuticals in aqueous environmental samples, Trends in Analytical Chemisty, 20(8), pp. 419-434.

Xie, H.Y. \& He, Y.Z. (2010). Green analytical methodologies combining liquid-phase microextraction with capillary electrophoresis, TrAC - Trends in Analytical Chemistry, 29(7), pp. 629-635. http://doi.org/10.1016/j.trac.2010.02.017

Zwiener, C. \& Frimmel, F.H. (2004). LC-MS analysis in the aquatic environment and in water treatment technology - a critical review. Part II: Applications for emerging contaminants and related pollutants, microorganisms and humic acids, Analytical and Bioanalytical Chemistry, 378(4), pp. 862-874. http://doi. org/10.1007/s00216-003-2412-1 


\section{Środowiskowe aspekty zastosowania chromatografii gazowej do oznaczania pozostałości farmaceutyków w różnych matrycach}

Streszczenie: W artykule przedstawiono możliwości wykorzystania chromatografii gazowej (GC, GC-MS) do oznaczania pozostałości farmaceutyków w różnych matrycach. W części pierwszej opisano środowiskowe aspekty zastosowania techniki chromatografii gazowej do takich analiz; w części drugiej innowacyjne sposoby oznaczania leków w środowisku; w części trzeciej wyniki analizy rynku w Polsce pod kątem wykorzystania techniki GC i GC-MS do takich badań.

Zgodnie z danymi literaturowymi, prezentowane tu metody zostały wykorzytane do analizy próbek rzeczywistych: ścieków, wód powierzchniowych, gleby, pochodzących z Pomorza i Zatoki Gdańskiej. Najwyższe stężenia leków stwierdzono w ściekach surowych, średnich - w ściekach oczyszczonych, a najniższe - w wodach powierzchniowych. Najczęściej wykrywanymi farmaceutykami były leki należące do grupy NLPZ: ibuprofen, paracetamol, diklofenak i naproksen. Wyniki badań polskiego rynku GC wskazują wyraźnie, że nieznaczna liczba podmiotów gospodarczych stosuje obecnie technikę GC do oznaczania leków w różnorodnych matrycach. Dzieje się tak na skutek braku przepisów prawnych w tej dziedzinie oraz braku własnych laboratoriów. 